\title{
Música Moderna Brasileira e suas Implicações de Esquerda*
}

\author{
Artigo/depoimento de Gilberto Mendes
}

Villa-Lobos, juntamente com Francisco Mignone e Camargo Guarnieri, são os pilares da música moderna brasileira, que começou entre os ano $10 \mathrm{e}$ 30. Villa-Lobos já era "moderno", até mesmo "pós moderno", antes de tudo, antes da famosa "Semana da Arte Moderna" de 1922, realizada com grande escândalo e repercussão no Teatro Municipal de São Paulo. As coisas estavam no ar, cubismo, futurismo, surrealismo, dadaísmo e outros "ismos". A lendária "Semana de 22 " veio conscientizar essas diversas tendências"modernas", tornando-se um marco na História artística brasileira.

Ao mesmo tempo que assumia e se colocava em dia com todas as técnicas modernas européias - elitistas, no fim das contas - a Semana proclamava a necessidade de uma arte autenticamente nativista, "pau Brasil", vale dizer, de certo modo nacionalista. As contradições estavam notadamente nos dois e entre os dois - principais líderes do movimento de 22, Oswald de Andrade e Mário de Andrade. Oswald de Andrade inscreveu-se logo a seguir no Partido Comunista Brasileiro, por coincidência fundado no mesmo ano de 1922, como consequiência do movimento anarquista de São Paulo, de imigrantes italianos e espanhóis. Oswald era comunista bem ao estilo "anos 20 ", convencido de que as massas um dia saberiam apreciar o "biscoito fino" de sua vanguarda literária.

Já Mário de Andrade não acreditava nisso e, alguns anos depois, escreveu um histórico documento rompendo com as diretrizes da Semana, taxandoas de classistas, divorciadas dos reais interesses do povo. Vale lembrar que Oswald de Andrade e Mário de Andrade são dois autores fundamentais do modernismo brasileiro.

Oswald se desligaria do Partido Comunista alguns anos depois, enquanto Mário de Andrade endureceu sua posição num sentido cada vez mais engajado, exercendo grande influência sobretudo entre os compositores brasileiros. Mário, além de escritor, era crítico de artes, folclorista, musicólogo; criador de Bibliotecas, Congresso de Língua Nacional Cantada, Departamento de Cultura de São Paulo, um homem de atividade assombrosa.

\footnotetext{
* Este artigo toi encomendado pela revista Musik und Gesellschaff da antiga RDA. não publicado após a reunificação alemã. Daí seu caráter informativo, tendo em vista um público desconhecedor da música brasileira. Sob outro aspecto, abre um leque de participaçâo marcante das esquerdas na música do Brasil. (N.E.)
} 
Villa-Lobos escapava um pouc mais à influência de Mário de Andrade, mas Guarnieri e Mignone, principalmente este último, ouviram muito suas críticas e orientação nacionalista. Camargo Guarnieri e Francisco Mignone eram típicos representantes da velha São Paulo dos anos 20 e 30, filhos de imigrantes italianos. Ainda nos anos 50, a pimeira tentativa de um cinema industrial à maneira de Hollywood foi feita por artistas italianos que vieram contratados para trabalhar nos estúdios da "Vera Cruz"; entre eles, Adolfo Celi, Luciano Salce Fabio Carpi, Ugo Lombardi; e que também trabalharam no histórico Teatro Brasileiro de Comédia, em fins dos anos 40 . Muito jovens, vieram tentar a vida no Brasil, como atores e diretores, a convite do empresário Franco Zampari, filho de italianos. Francisco Mignone, por essa época, também fez trilhas sonoras para os filmes da Vera Cruz, juntamente com Camargo Guarnieri e o italiano Henrique Simonetti.

Mignone sempre foi um homem de esquerda, no passado muito ligado ao Partido Comunista, às causas da paz e amizade entre os povos. Foi quem, pela primeira vez, regeu a Sinfonia de Leningrado, de Shostakovitch, no Brasil, logo após o término da II Guerra Mundial.

Villa- Lobos é olhado com reservas pela esquerda radical, por que foi muito beneficiado pelo Estado Novo do então ditador Getúlio Vargas. E teve simpatias pelo nazismo, nos anos 30 , chegando a ser convidado para uma viagem à Alemanha no famoso dirigível "Graf Zepellin". Seus sonhos eram a educação Musical de massa, das crianças, através do canto orfeônico em grandes estádios, para o que conseguiu o apoio de Getúlio Vargas. Mas era, na verdade, uma figura contraditória, como o próprio ditador Vargas, que foi considerado pelos trabalhadores como "o pai dos pobres", carinhosamente chamado de "Ge-ge".

Nos anos 40, fugindo do nazismo, vem para o Brasil o musicista alemāo Hans-Joachim Koellreutter, que iria desempenhar importantíssimo papel na História da música brasileira a partir de sua chegada. Ao mesmo tempo em que introduzia no país as técnicas alemãs de Schoenberg e Hindemith, o dodecafonismo, por exemplo, altamente elitista, Koellreutter, com seus companheiros e alunos, lançou em 1964 o famoso "Manifesto Música Viva", no Rio de Janeiro, que na realidade não era um manifesto somente social, como se poderia pensar, mas um manifesto altamente político bem sintomático do clima de pós-guerra. Fala da música como um "produto da vida social... reflexo do essencial na realidade... superestrutura de um regime... compreendendo que o artista é produto do meio e que a arte só pode florescer quando as forças produtivas tiverem atingido um certo nível de desenvolvimento... não há arte sem ideologia... repele o formalismo, pois a forma corresponde ao contcúdo nela representado... compreendendo que a tendência 'arte pela arte' surge num terreno de desacordo insolúvel com o meio social, bate-se pela concepção utilitária da arte... acreditando na função socializadora da música, por um mundo novo... "etc.etc.

Mas o manifesto também combatia o academismo e o nacionalismo estreito, que exalta sentimentos de superioridade nacional, estimula tendências ego- 
cêntricas e individualistas que separam os homens, originando forças disruptivas. Mas naquele momento, os principais compositores do Grupo Música Viva, Cláudio Santoro, Guerra Peixe, Eunice Katunda, Edino Krieger, eram ligados, direta ou indiretamente, ao Partido Comunista Brasileiro, que vivera na legalidade entre 1945 e 1948, com muita presença na opinião pública. Ao mesmo tempo, eram os primeiros compositores atonais e dodecafônicos basileiros, na vanguarda musical de então. Contradição viva!

Cláudio Santoro fez notável carreira, principalmente nos países curopeus do Leste, tendo se apresentado muitas vezes na União Soviética, Tchecoslováquia e Polônia. Na União Soviética gravou um disco com sua "IV Sinfonia" (1953), com coros (composta um pouco à maneira de Shostakovitch), também conhecida como "Sinfonia da Paz", com texto da poetisa comunista de Santos Antonieta Dias de Moraes. Outra obra significativa desse seu engajamento político foi o "Canto de Amor e de Paz", para orquestra de câmara. Obras que refletem o Movimento pela Paz dos anos pós II Guerra.

Eu mesmo, aluno de Santoro por essa época, também compus várias cançōes engajadas, como "Lamento", "Peixes de Prata" (texto também de Antonieta Dias de Moraes), "Pedro meu Amigo" (texto de Tereza de Almeida, composta $\mathrm{em}$ homenagem ao meu amigo, o grande jornalista comunista Pedro Mota Lima, que ia a Santos nos ensinar o marxismo, quando foi anistiado pelo Presidente Juscelino Kubitschek).

Essa preocupação política acabou levando os principais compositores do Grupo Música Viva a romperem com o dodecafonismo e atonalismo aprendidos com Koellreutter, e a um retorno ao nacionalismo musical. Isto também aconteceu como conseqüência da forte repercussão que teve no Brasil a discussão mundial em torno do Manifesto Zhdanov. Este novo nacionalismo tinha como modelos os signos musicais do realismo socialista soviético, adotados pelo que eles tinham de simbólicos. Era uma "griffe" para a sua música política. Outras obras significativas desse período foram a "Suíte Sinfônica No.1", de Guerra Peixe, que chegou a ser gravada em disco pela Orquestra Estadual de Moscou, sob direção do regente italiano ( radicado no Brasil) Edoardo Guarnieri, também comunista (e pai do famoso ator e autor teatral Gianfrancesco Guarnieri, igualmente comunista); e o "Canto do Soldado Morto", de Eunica Katunda, com texto do poeta comunista Rossini Camargo Guarnieri, irmão do compositor Mozart Camargo Guarnieri. Ao mesmo tempo, como grande pianista que também era, Eunice Katunda foi divulgadora no Brasil da obra de Schoenberg e, principalmente, de Hindemith. Mais contradição!

O compositor Camargo Guarnieri aproveitou a ocasião favorável para o lançamento de uma também historica "Carta Aberta" contra o dodecafonismo, na mais pura linguagem zhdanovista, apesar de ele nāo ser comunista (seu irmão Rossini, este do Partido Comunista, deve the ter dado o manifesto soviético para ler). Nessa "Carta Aberta", datada de novembro de 1950 e publicada no jornal "O Estado de São Paulo", Guarnieri escreve que "é preciso que se diga a esses jovens compositores que o dodecafonismo, em Música, corresponde ao Abstracionismo, em Pintura, ao Hermetismo, em Literatura, ao 
Existencialismo, em Filosofia, ao charlatanismo, em Ciência... É a expressão característica de uma política de degenerescência cultural, um ramo adventício da figueira-brava do Cosmopolitismo..."

A efervescência político-social daquele momento, somada a esses dois manifestos, de Zhdanov e Guarnieri, mais a coincidência entre pontos de vista de Zhdanov e de Mário de Andrade, em seu famoso "Ensaio sobre a Música Brasileira", deram invulgar força à corrente nacionalista no Brasil. Indiscutíveis se tornaram, entāo, as palavras de Mário em seu "Enșaio", sacralizadas, escritas uns 25 anos antes do manifesto de Zhdanov, o que the dava uma autoridade profética:"... a obra não é brasileira, como é antinacional (escreveu sobre determinada música). E socialmente o autor dela deixa de nos interessar. Digo mais: por valiosa que a obra seja, devemos repudiá-la, que nem fez a Rússia com Stravinsky e Kandinsky... O critério histórico atual de Música Brasileira é o da sua manifestação musical que, sendo feita por brasileiro ou indivíduo naturalizado, reflete as características musicais da raça. Onde estão elas? na música popular..."

Eram estranhas essas palavras, partindo de um autêntico intelectual de vanguarda, de um dos pilares da literatura moderna brasileira. Na verdade, isso refletia a dialética que vem marcando as artes brasileiras entre vanguarda e política. A partir de então, não houve compositor no Brasil que compusesse numa linha de vanguarda. Todos eram nacionalistas.

Até fins dos anos 50, alguns compositores de São Paulo, depois de conhecidos pelo nome Grupo Música Nova, resolveram retomar os ideais do Manifesto Música Viva, de Koellreutter, e se colocar em dia com com as modernas técnicas de composição da época, valendo-se do apoio e mesmo orientação do maestro Olivier Toni, que dirigia então a Orquestra de Câmara de São Paulo (Toni estudara com Koellreuter e Camargo Guarnieri; portanto, a verdadeira síntese dialética dessa velha antinomia vanguarda versus nacionalismo). $R$ tomam o dodecafonismo no seu estágio de serialismo integral, com base no estudo autodidático das obras de Stockhausen, Boulez, Nono, Pousseur, Berio. Depois, esses compositores freqüentariam os cursos de Darmstadt. Éramos Rogério Duprat, Willy Corrêa de Oliveira, Damiano Cozzella e eu. Experimentamos então a música aleatória, microtonal, concreta, gestual (teatro musical), utilizando novos grafismos e meios mistos.

Nossa música era de extrema preocupação vanguardista e obedecia aos princípios que nós mesmos estabelecemos em nosso "Manifesto Música Nova", lançado em 1963, em São Paulo, pela revista de arte e de vanguarda "Invenção", porta-voz da poesia concreta brasileira. Mas a política estava também em nossas cabeças. O manifesto falava $\mathrm{em}$ "...compromisso total com o mundo contemporâneo; reavaliação dos meios de informação: importância do cinema, do desenho industrial, das telecomunicações, da máquina como instrumento e objeto: cibernética... a alienação está na contradição entre o estágio do homem total e seu próprio conhecimento do mundo... elaboração de uma teoria dos afetos (semântica musical) em face das novas condições do binômio criação-consumo... por uma arte participante... "E terminava com estas pala- 
vras de Maiakowski: "Sem forma revolucionária não há arte revolucionária".

Rogério Duprat escrevera anteriormente, nos anos 50, na imprensa comunista de São Paulo, no jornal "Notícias de Hoje"; assim como eu tive, a meu cargo, na mesma época, a doutrinação política através da música, em uma frente de massa do Partido Comunista, no Clube de Arte de Santos, que sucedeu o artigo Clube de Gravura, fundado pelo pintor comunista - também de Santos - Mário Gruber. Note-se que Santos e Recife foram as cidades mais comunistas do Brasil nesse período. Interessei-me pela poesia concreta porque, além de sua pesquisa de uma linguagem poética nova, experimental, estrutural, os poemas falavam também de greve, passeata, fome. Mesmo em plena elaboração, com meus companheiros, de uma pretendida "Neue Musik" brasileira de vanguarda, eu procurava, de preferência, entre a poesia concreta, um texto político, de crítica, como o poema "Beba Coca-Cola", de Décio Pignatari, que coloquei em música em meu "Motet in Re Menor", por que terminava caracterizando essa bebida como algo que sai de uma "cloaca".

Para o Festival Música Nova de Santos (a mais velha mostra de toda a América Latina da música de vanguarda feita em todo o mundo), que fundei em 1962, transferi o mesmo tipo de doutrinação política (sempre que cabia, e, desta vez velada, pois começavam então os amargos anos da ditadura, a partir do golpe militar de 1964) através da música, que realizara no velho Clube de Arte dos anos 50. Foi assim que, ao lado de Stockhausen e Boulez, fomos divulgando também a onra de Hanns Eisler, Cornelius Cardew, com toda a sua carga semântica política, e promovendo discussões a seu respeito: Bem como obras na mesma linha de novos compositores, como o chileno Sergio Ortega, o italiano Luca Lombardi, o autríaco Wilhelm Zobl, o grego Thanos Mikroutsikos.

$\mathrm{E}$, nesses últimos tempos, como consequência da abertura política que começou a se processar no Brasil, também voltei a dar atenção à música politicamente engajada - a partir de $84 / 85$ - compondo obras corais para a campanha DIRETAS JÁ ("Mamãe eu quero votar"), de protesto pela explosão de uma vila operária ("Vila Soco, Meu Amor") e de denúncia ("Vão entregar as estatais para as multinacionais"); e um tango para piano em homenagem aos três padres ministros da Nicarágua. E abrimos um espaço expressivo, no Festival Música Nova de Santos, à música com implicações políticas, trazendo recentemente ao Brasil novos compositores europeus dessa linha de preocupações, como Lombardi, Zobl, Mikroutsikos e o extraordinário norte-americano Frederick Rzewski.

São poucas, no entanto, as obras brasileiras de outros compositores eruditos com conotações políticas. Ainda podemos citar como importantes politicamente, a obra de Aylton Escobar "Poemas do Cárcere" (1968), sobre poema de Ho-Chi-Min, cantata para solista, coro e orquestra; e a "Elegia Violeta para Monsenhor Romero" (1980), de Jorge Antunes, para orquestra e coro infantil, "in memorian" desse arcebispo assassinado pelo terrorismo de direita em El Salvador. Jorge Antunes também participou, em Brasília, da campanha DIRETAS JÁ, com obras suas. 
Da novíssima geração, podemos destacar Rubens Ricciardi, voltado à música politicamente engajada dentro de uma tradição que remonta a Eisler; e Florivaldo Menezes Filho, também politicamente interessado, dentro de uma visāo trotskista, mas voltado à tradiçāo estruturalista da música de Schoenberg e Webern. Os dois ex-alunos, na Universidade de São Paulo, do compositor Willy Corrêa de Oliveira, um dos signatários do Manifesto Música Nova - e também o mais intelectualizado e térico, especialmente no campo da semiótica musical - que há uns anos rompeu espetacularmente co toda a vanguarda, com sua própria obra, renegando-a; e superando Eisler e Cardew em radicalidade, passou a compor só com fins de doutrinação política, junto às Comunidades Eclesiais de Base. Da Música Nova para a Igreja Nova, da Teologia da Libertação, um passo fora do comum, mas não de todo surpreendente, nos estranhos caminhos da música de hoje no Brasil e no mundo. Caminhos que refletem bem, na América Latina, as angústias, as perplexidades, as responsabilidades e tomadas de posição do artista frente à opressão e à miséria. 